\title{
SHORT-TERM INTERACTIONS BETWEEN ATMOSPHERIC SYNOPTIC CONDITIONS AND SEA-ICE BEHAVIOUR IN THE ARCTIC
}

by

\author{
James A. Maslanik and Roger G. Barry
}

(Cooperative Institute for Research in Environmental Sciences (CIRES), University of Colorado, Boulder, CO 80309-0449, U.S.A.)

\begin{abstract}
Passive microwave data (SMMR) and data from drifting buoys are used to examine atmosphere-ice interactions during autumn 1978 through autumn 1982 in the Canada Basin. SMMR brightness temperatures, ratios, and calculated ice concentrations are compared with surface pressure, temperature, buoy motion, and winds at a coincident location to identify possible linkages operating on daily to weekly time-scales. Inter-annual differences in temperature, pressure, and ice conditions inferred from SMMR data are discussed. Periods of reduced ice concentration as estimated by SMMR are found to occur during late summer and early autumn in 1980, 1981, and 1982. The decreases in ice concentration are concurrent with low-pressure systems and increased divergence in the buoy field in 1980 and 1981. These apparent decreases in ice compactness are discussed in relation to previously reported areas of reduced concentration interpreted from ESMR data. Evidence to support a postulated relationship between atmospheric low pressure and divergence of ice under free-drift conditions is demonstrated for the summer of 1980.
\end{abstract}

\section{INTRODUCTION}

Given the predominant use of relatively low temporal and spatial resolution data in climatological studies of ice-atmosphere interactions, the question arises as to whether important processes involving the ice and atmosphere might be occurring in relatively small areas (e.g. a few thousand $\mathrm{km}^{2}$ ) over time-scales of days to weeks. For example, theoretical drift calculations (Hibler, 1974) indicate that low atmospheric pressure should produce a divergence of ice under free drift. Recent analysis of Arctic drifting buoys (McLaren and others, 1987) has shown an apparent relationship between persistent low pressure in late summer in the Canada Basin and reversal of the motion of the Beaufort Gyre lasting several weeks. Thus, conditions exist in the Canada Basin that theoretically should lead to reduced ice concentration for localized areas. The goal of this study is to determine whether observational evidence exists for short-period interactions between sea ice and the atmosphere in the northern Canada Basin with particular emphasis on the postulated linkage between low pressure and reduced ice concentration.

\section{DATA AND METHODOLOGY}

Information on ice concentration and condition for November 1978 through November 1982 were extracted from multi-frequency passive microwave data. Additional information was derived from ice charts and visible and infra-red Defense Meteorological Satellite Program (DMSP) satellite imagery. Concurrent atmospheric conditions are retrieved from gridded data sets and correlated with ice behaviour to explore the strength and direction of ice-atmosphere linkages.

\section{Passive microwave imagery}

Passive microwave data used in this study were acquired by the Nimbus 7 Scanning Multichannel Microwave Radiometer (SMMR). SMMR collects data on alternate days in five channels $(6.6,10.7,18.0,21.0$, and $37.0 \mathrm{GHz})$, with two polarizations (horizontal and vertical) per channel. The instantaneous field of view is $55 \mathrm{~km} \times 41 \mathrm{~km}$ and $27 \mathrm{~km} \times 18 \mathrm{~km}$, respectively, for the 18 and $37 \mathrm{GHz}$ channels used here. Resolutions of calibrated and gridded data are typically reduced to $60 \mathrm{~km} \times 60 \mathrm{~km}$ and $30 \mathrm{~km} \times 30 \mathrm{~km}$ for the 18 and $37 \mathrm{GHz}$ channels.

The operational NASA Team algorithm (Cavalieri and others, 1984) was used to calculate ice concentration from the SMMR data. Differences between the low brightness temperatures and large polarization of open water relative to sea ice are used to derive ice concentration. Since polarization and brightness temperatures are also affected by surface conditions, such as snow melt, pond coverage, and ice thickness, the calculated ice concentrations actually represent the composite of all such conditions in the ice pack. For this reason, the polarization ratio (PR) and gradient ratio (GR), as well as brightness temperatures, were used to interpret the brightness-temperature patterns resulting in reduced ice concentration as calculated by the NASA Team algorithm.

\section{Meteorological data}

The meteorological and surface-data sets used include gridded pressures and temperatures provided by the Arctic Ocean Buoy Program (commencing with Thorndike and Colony (1980)). Buoy-measured temperatures are subject to errors of several degrees, mainly due to radiational heating within the buoy housings, and may be more representative of snow-cover temperatures than of air temperatures (Thorndike and Colony, 1981). Biases in pressure are about $1 \mathrm{mbar}$, while errors in interpolated buoy velocities are estimated to be in the range of $0.01-0.02 \mathrm{~cm} / \mathrm{s}$ where buoy density is high (Thorndike and Colony, 1983). Geostrophic winds were calculated from the gridded pressure data for 1979 and 1980. Buoy divergence was estimated using the method described by Colony and Thorndike (1981). For all comparisons between the passive microwave and buoy data, the nearest buoy-data grid to $84^{\circ} \mathrm{N}, 155^{\circ} \mathrm{W}$ was chosen for analysis $\left(84^{\circ} \mathrm{N}, 150^{\circ} \mathrm{W}\right.$ for pressure and temperature; $82^{\circ} \mathrm{N}$, $160^{\circ} \mathrm{W}$ and $86^{\circ} \mathrm{N}, 160^{\circ} \mathrm{W}$ for buoy velocities). Errors introduced by this difference in location between the SMMR observations are considered to be small due to the low-frequency variability of the gridded temperature and pressure fields.

\section{ICE CHARACTERISTICS IN THE CANADA BASIN}

Sea ice in the Canada Basin is predominantly multi-year ice; submarine observations in early August 1970 showed a mean thickness of $2.4 \mathrm{~m}$, with open leads and young ice $(<30 \mathrm{~cm})$ estimated to account for $4 \%$ of the area (McLaren, unpublished). The mean long-term ice drift in the Beaufort Gyre is clockwise (anti-cyclonic), with a 
tendency for a reversal of the motion in late summer, commonly in August, associated with persistent cyclone systems (McLaren and others, 1987). Operational ice charts, produced from interpretations of ship and aircraft observations, visible-channel and infra-red satellite imagery, and passive microwave data, typically indicate $10 / 10$ ice cover in the central Canada Basin. The exception occurs during years when highly fractured ice or large numbers of leads are observed in the pack. For example, the Navy/NOAA ice chart for 26 August 1980 noted the occurrence in the central Canada Basin of "the most extensive area of weakness in the ... ice pack since the late summer of 1976" with the ice concentration estimated as $7-8 / 10$. Low concentrations are also shown in NOAA AVHRR imagery during the same time (personal communication from D. Barnett). Large numbers of leads and fractures were also noted in DMSP visible-channel imagery for June 1980, with the fractures persisting for several weeks.
Microwave-signature changes and meteorological conditions Figures 1 and 2 present the variation over time of brightness temperature at approximately $84^{\circ} \mathrm{N}, 155^{\circ} \mathrm{W}(18$ $\mathrm{GHz}$, horizontal polarization), surface temperature, sea-ice concentration calculated using the NASA Team algorithm, and surface pressure. Since the objective of this work is to study processes occurring over relatively small areas, passive microwave data for a single $900 \mathrm{~km}^{2}$ SMMR pixel were analyzed in detail. This site was selected to correspond to a region of persistent low pressure in August 1980 (McLaren and others, 1987). To examine the local variability of ice conditions, the time series of SMMR-derived ice concentrations derived from SMMR observations at approximately $83^{\circ} \mathrm{N}, 155^{\circ} \mathrm{W}$ and $83^{\circ} 30^{\prime} \mathrm{N}, 155^{\circ} \mathrm{W}$ were correlated with the $84^{\circ} \mathrm{N}, 155^{\circ} \mathrm{W}$ values for the entire 1978 through 1982 period, and for summers of these years, when local differences are likely to be greatest. Correlation coefficients between $84^{\circ} \mathrm{N}, 155^{\circ} \mathrm{W}$ and $83^{\circ} \mathrm{N}, 155^{\circ} \mathrm{W}$ are 0.91 for the full series and 0.90 for summer data
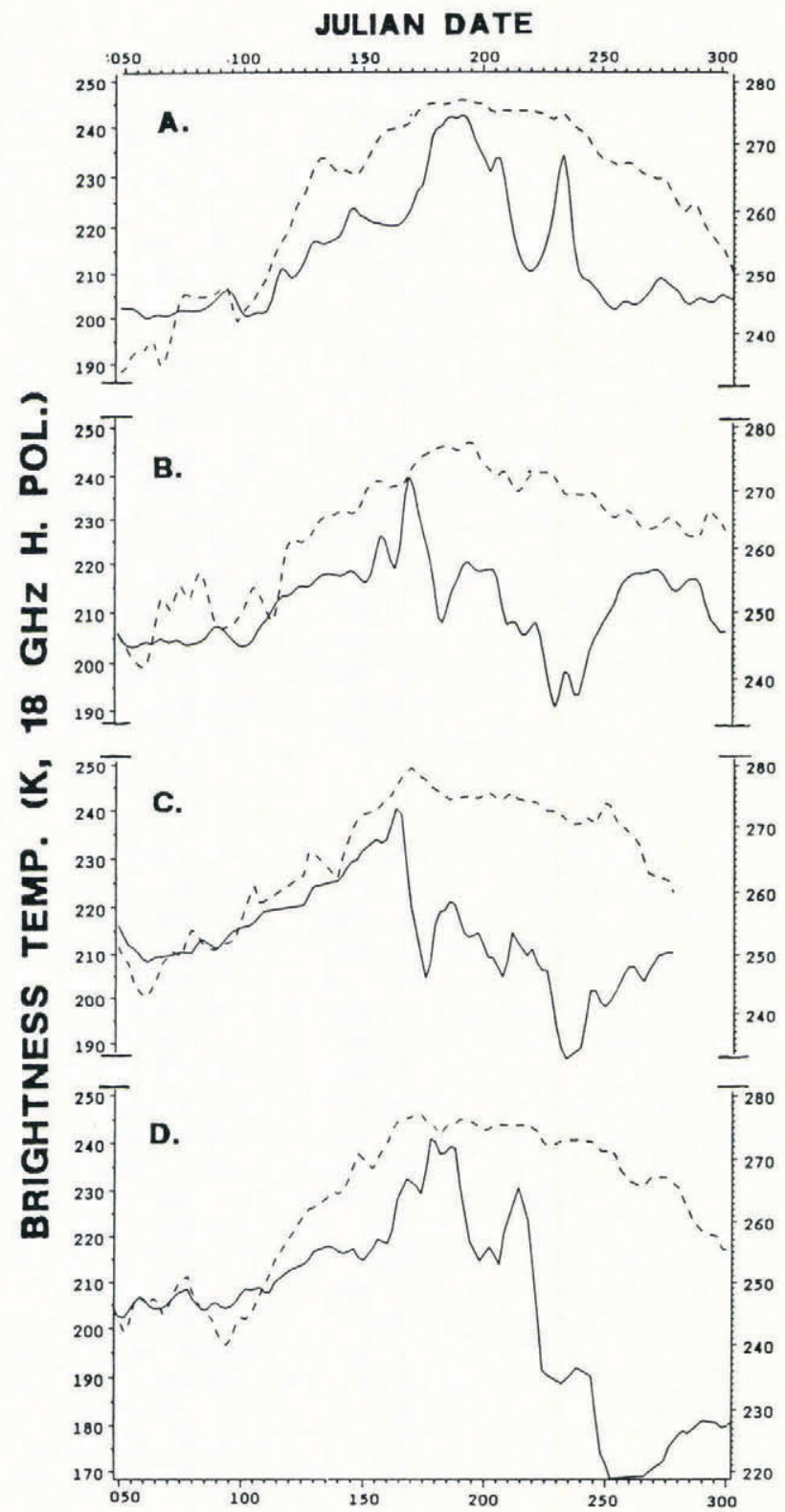

\section{JULIAN DATE}

Fig. 1. Time series of SMMR passive microwave brightness temperatures ( $18 \mathrm{GHz}$, horizontal polarization; solid line) measured at $84^{\circ} \mathrm{N}, 155^{\circ} \mathrm{W}$ and buoy-recorded air temperatures (dashed line) from grid location $84^{\circ} \mathrm{N}$, $150^{\circ} \mathrm{W}$ of the analyzed buoy field. (A) 1979, (B) 1980, (C) 1981 , (D) 1982.

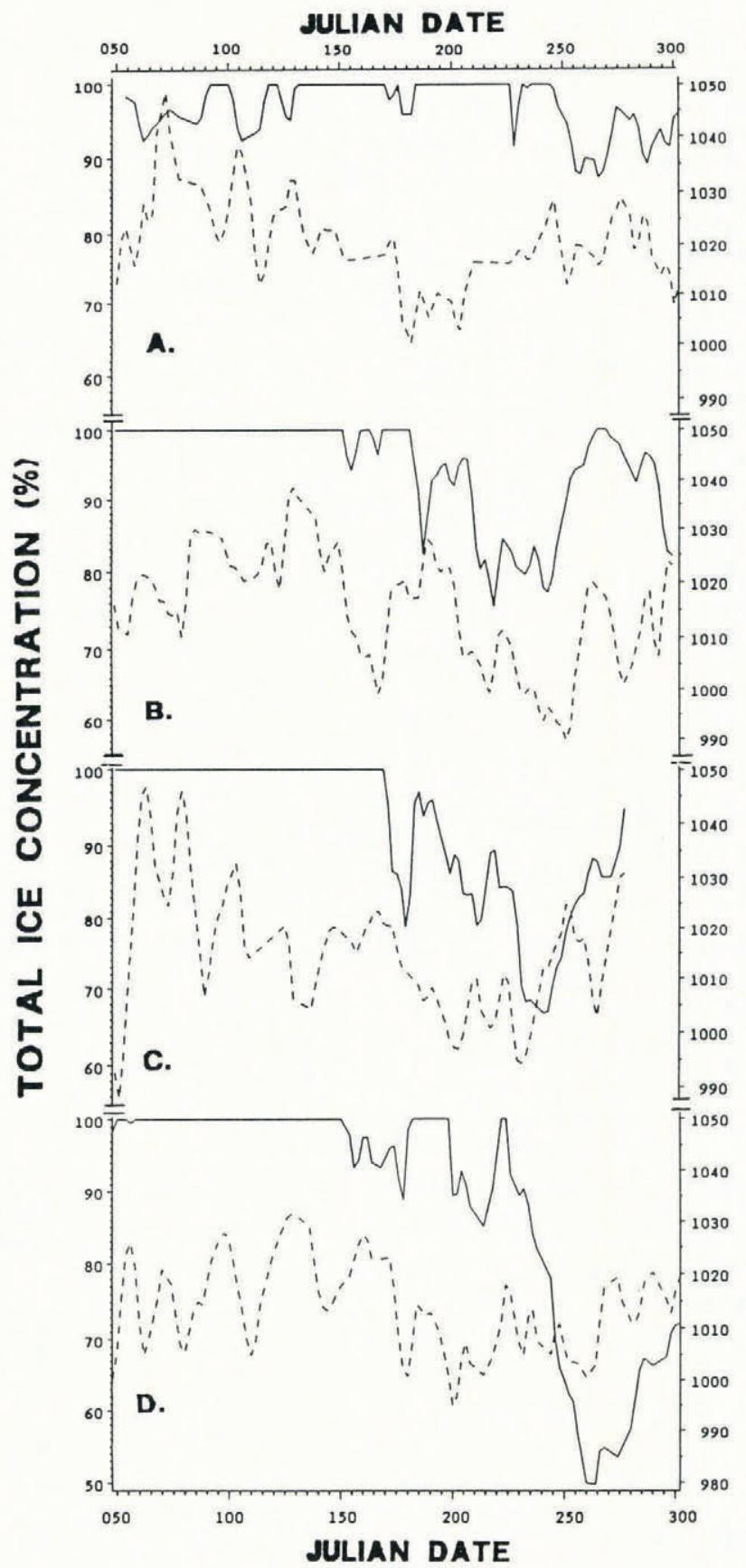

Fig. 2. Time series of SMMR-derived ice concentrations (solid line) measured at $84^{\circ} \mathrm{N}, 155^{\circ} \mathrm{W}$ and buoy-recorded surface pressures (dashed line) from grid location $84^{\circ} \mathrm{N}$, $150^{\circ} \mathrm{W}$ of the analyzed buoy field. (A) 1979, (B) 1980, (C) 1981, (D) 1982 . 
Correlations between $84^{\circ} \mathrm{N}, 155^{\circ} \mathrm{W}$ and $83^{\circ} 30^{\prime} \mathrm{N}, 155^{\circ} \mathrm{W}$ are 0.94 and 0.93 for the full series and summer data, respectively. Unless otherwise noted, the quoted correlation coefficients are significant at the 0.05 level, with serial correlation taken into account through an appropriate reduction in degrees of freedom. A difference of means test between the $84^{\circ} \mathrm{N}, 155^{\circ} \mathrm{W}$ data and the other locations rejects unequal means at the $95 \%$ confidence level.

Temperatures measured by drifting buoys begin to rise in early March and reach $0^{\circ} \mathrm{C}$ about 20 June in 1979 and 1980 (Julian day 171). Although the effects of radiational heating in the buoys and differences between air and surface temperatures make precise comparisons difficult, the $18 \mathrm{GHz}$ brightness temperatures show a clear response to this change in physical temperature, with a concurrent increase through spring and into early summer. As noted by Anderson (1987), the onset of melt in the sea ice is indicated by an abrupt rise in brightness temperatures in Figure 1 caused by the increase in emissivity associated with small amounts of liquid water in the snow/ice pack. The rise in brightness temperature in 1979 is more gradual and is delayed by several days following the first above-freezing buoy temperatures. This discrepancy may be due to the above-mentioned observational errors, or may represent differences in melt progression due to weather patterns or ice-surface conditions. For all years studied, a temporary reduction in brightness temperature and calculated ice concentration occurs following these periods of melt, perhaps due to the presence of melt ponds. Subsequently, in August 1980 (Julian days 214-244) and in late summer 1981 and 1982, SMMR-estimated ice concentrations again decrease below the range typically expected in the Canada Basin.

It is possible that the reduced ice concentration estimated by SMMR may be attributable to other effects such as melt ponds. Most of August in 1980 is characterized by considerably lower brightness temperatures and higher PR than is the case in 1979. These conditions persist throughout August into the beginning of September, during which time observed physical temperatures are below freezing, with low pressure dominating most of this period. Although extensive melt-ponding could produce such microwave responses, the combination of long duration of this signal combined with low physical temperatures appears to rule out this possibility. Other evidence indicates that melt ponds typically begin to refreeze in August (Barry, 1983). The SMMR-calculated ice concentration of about $80 \%$ agrees well with the Navy/NOAA ice-chart estimate of 7-8/10 ice for late August 1980 and appears similar to an episode noted by Zwally and Walsh (1987), who described a strong cyclonic system in early December 1980 , near $80^{\circ} \mathrm{N}$, $165^{\circ} \mathrm{W}$, which was associated with a $30-40 \%$ reduction in multi-year ice concentration, estimated from SMMR data. Lower concentrations of multi-year ice then persisted through January 1981. Gloersen and others (1978), in an early analysis of single-frequency passive microwave data from Nimbus-5, found more extreme, but similarly timed and located decreases in brightness temperature, which they concluded represent ice concentrations of $50-60 \%$. Campbell and others (1984) and Parkinson and others (1987) supported the view that the observed drops in brightness temperature are due to reductions in ice concentration. However, Crane and others (1982) argued that the ESMR signatures represented a combination of surface melt-pond effects and some increase in small openings, rather than a major polynya.

DMSP imagery for 10 September 1982 (Fig. 3) clearly shows areas of reduced concentration within the Canada Basin ice pack characterized by irregular patterns of floes and open water. Based on World Meteorological Organization terminology, these areas are best categorized as areas of weakness (reduced concentration surrounded by high-concentration ice) or as open pack ice rather than as polynyas. SMMR data for 10 September 1982 show $18 \mathrm{GHz}$ horizontal polarization brightness temperatures of less than $170 \mathrm{~K}$ and ice concentrations less than $70 \%$ in the area noted in the DMSP image in Figure 3, and in other areas further north and west hidden by cloud cover where the SMMR-derived concentrations are less than $60 \%$ in some locations. Ice charts for September 1982 show a distribution of $7-9 / 10$ ice, in general agreement with the SMMR data. Similar but more extensive areas of reduced concentration

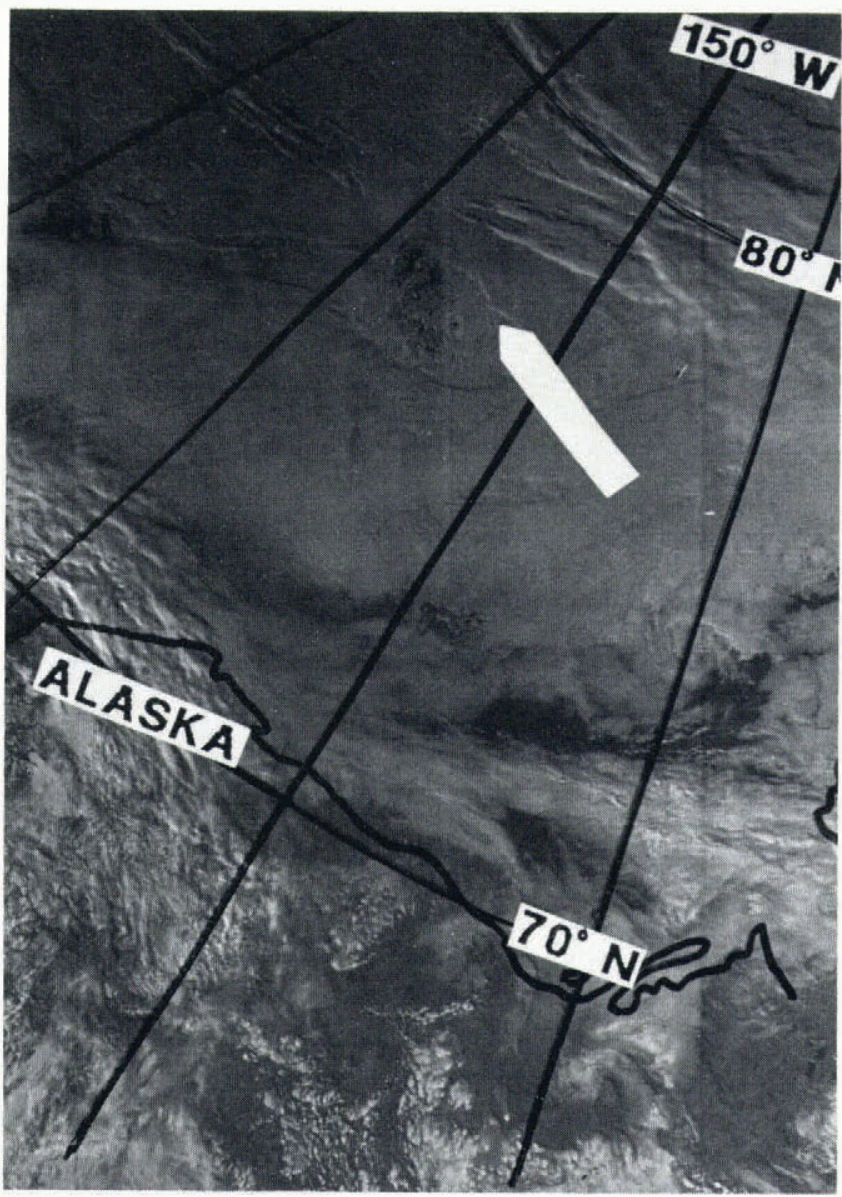

Fig. 3. Defense Meteorological Satellite Program visiblewavelength images $(0.6 \mathrm{~km}$ resolution) showing areas of reduced-concentration ice within the Beaufort Sea ice pack on 10 September 1982. Area of low concentration is marked by the white arrow.

can be seen in satellite imagery for several other years. This direct evidence for areas of reduced-concentration ice reinforces the interpretation that at least some of the lower concentrations detected by SMMR in other years, for which there is no corroborating evidence, are in fact real. These results require modification of the widely held view of consistent high-concentration ice in the central Arctic and justify a more detailed analysis of possible ice-atmosphere linkages. During the interval of reduced ice concentration in August 1980 (Julian days 214-244), surface pressures were lower than earlier in the summer, and in marked contrast to the anti-cyclonic regime of winter and spring months. McLaren and others (1987) showed that quasi-stationary cyclone systems were especially common in August 1980, in contrast to 1979 . Figure 4 shows a comparison of cyclone tracks interpreted from the Arctic buoy data for summer 1979 and summer 1980. The tightly grouped tracks in Figure $4 \mathrm{~b}$ demonstrate the localized and persistent nature of the 1980 depressions. The intensity of this quasi-stationary system is illustrated by central pressures below $980 \mathrm{mbar}$ reported on 28 August 1980.

This association between persistent cyclone activity and the reduced ice concentrations apparent in Figure 2 for 1980 and 1981 (but not 1982) supports the calculations by Hibler (1974) indicating that, for free-drift conditions approximated by lower ice compactness in summer, ice located in a region of cyclonic circulation will undergo divergence. The observed time series of ice concentration in 1980 strongly resembles the ice compactness modelled by Hibler (1979, figs $19 \mathrm{~b}$ and 21b) for an ice simulation forced by atmospheric data from 1963. Atmospheric conditions during that summer were similar to those in 1980. To establish the physical linkages involved in the observed co-occurrence between pressure and reduced ice concentration, the leads and lags of correlations between pressure, ice motion, and ice concentration are investigated. 
Based on Hibler's (1974) calculations, an inverse correlation between pressure and ice divergence would be expected during late summer, if ice concentrations are low enough to approximate free drift. For the Canada Basin, the information presented in Figures 2 and 3 suggests that in 1980,1981 , and 1982 such conditions would be present following the prolonged period of melt in mid-summer. Coefficients of correlation between pressure and ice divergence were calculated from the gridded buoy data (smoothed using a three-point moving weighted average) for 1 July-30 September (Julian days 182-273) for each melt season from 1979 to 1982 . The highest correlations of about 0.63 occur at zero lag in 1980 and 1981 , with an asymmetrical distribution of lagged correlations suggesting that pressure leads divergence by about $2 \mathrm{~d}$. Virtually no correlation exists in 1979 and 1982. The observed ice motion is much more spatially variable than atmospheric pressure, and hence interpolated divergence values may not accurately reflect regional conditions. McLaren and others (1987) showed that the divergence calculated from the gridded buoy velocities over a nine-point grid centered on the Beaufort Gyre was of the order of $0.5 \times 10^{-7} \mathrm{~cm} \mathrm{~s}^{-1}$ in late August-early September 1980, indicating a regionalscale divergence. As an estimate of the spatial variability of buoy divergence, concurrent values were calculated for the $82^{\circ} \mathrm{N}, 160^{\circ} \mathrm{W}$ and $86^{\circ} \mathrm{N}, 160^{\circ} \mathrm{W}$ grid locations. Correlation coefficients between these two locations for each summer were highest in 1980 and $1981(0.77$ and 0.71$)$ at zero lag. Correlations in other years ranged from 0.59 at zero lag in 1979 to 0.15 (not significant) at zero lag in 1982. The gridded buoy divergences therefore show considerable local variability.

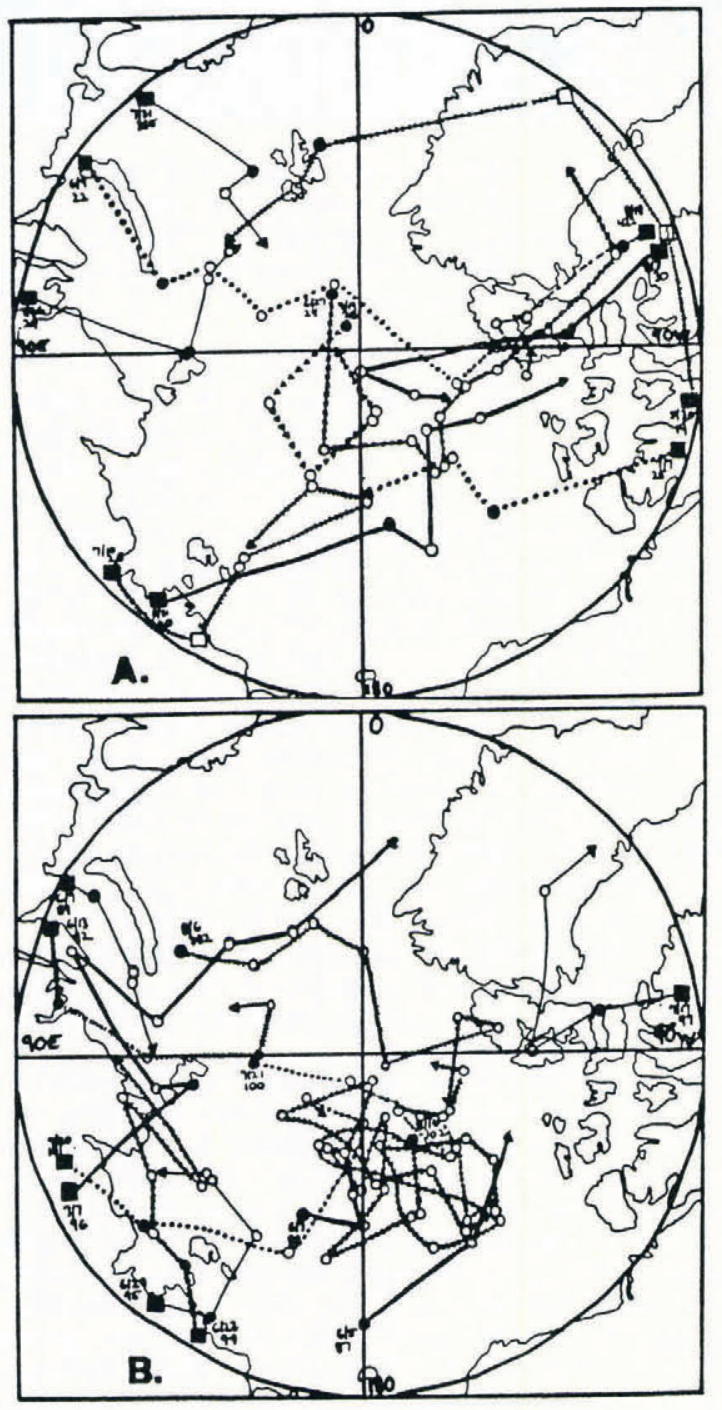

Fig. 4. Comparison of cyclone tracks interpreted from the analyzed Arctic buoy pressure fields for (A) summer 1979 and (B) summer 1980 (unpublished data of M.C. Serreze).

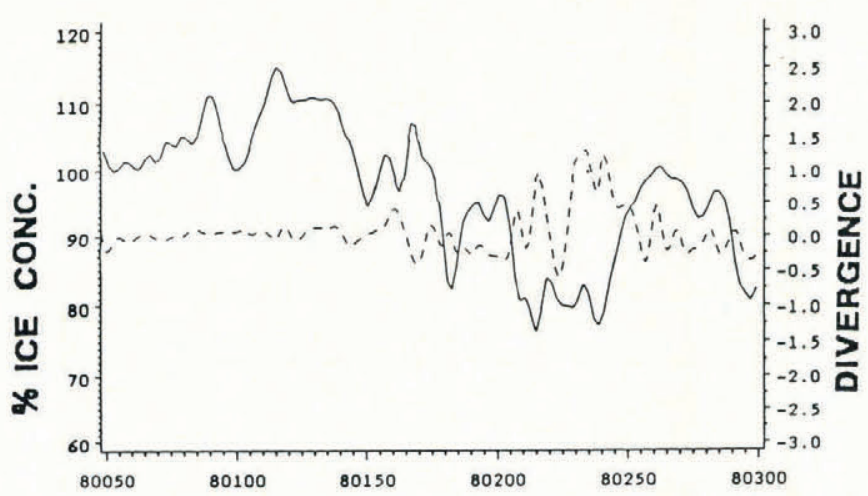

MULAN DATE

Fig. 5. SMMR-derived ice concentrations (solid line) at $84^{\circ} \mathrm{N}, 155^{\circ} \mathrm{W}$ and buoy divergence (dashed line) in $\mathrm{cm} \times$ $10^{-7} \mathrm{~s}^{-1}$ at $82^{\circ} \mathrm{N}, 160^{\circ} \mathrm{W}$ for mid-February through October 1980.

Next, the degree of inverse relationship between ice divergence and ice concentration is examined assuming that divergence should be reflected as reduced ice concentration. Figure 5 shows that divergence is greatest during the period of low ice concentration in August 1980. The strongest inverse correlation $(-0.56)$ occurs in 1980 , with divergence leading observed ice concentration by one SMMR observation period, or $2 \mathrm{~d}$. Non-significant correlations are found in 1979, 1981, and 1982. For 1980, a case can be made that during the time that the passive microwave data indicate reduced concentration ice, the pack is indeed diverging. Little ice divergence is expected in 1979 due to the infrequent cyclones. The lack of correspondence in the other 2 years is most probably a result of the spatial variability of the gridded buoy velocities or different relationships between buoy motion and local ice concentrations in those years.

Given that the above analysis demonstrates a correlation between pressure and ice divergence and between ice divergence and concentration, a direct correspondence between pressure and ice concentration should exist, with the likeliest agreement occurring in 1980. Comparison of the summer time series of ice concentration and pressure for 1979 through 1982 shows the strongest positive correlation $(0.57)$ in 1980, with pressure leading ice concentration by 4 d. In 1979, a negative correlation of -0.63 occurs at zero lag. If the observed divergence in 1980 was a function of advection in a single direction rather than in several directions as implied by the pressure-divergence hypothesis, strong correlations would be expected between ice concentration and wind speed and direction. For the 1979 and 1980 late-summer cases, wind speed and direction were calculated from gridded buoy-measured pressures and compared to ice concentration. Correlations between ice concentration, wind speed, and $U$ and $V$ components were insignificant for all lags in both 1979 and 1980 .

\section{CONCLUSIONS}

Comparisons of passive microwave data and buoy measurements have identified some potential ice-atmosphere interactions that merit further investigation:

(1) Evidence that areas of reduced-concentration ice occur within the Canada Basin ice pack agrees with previous interpretations of ESMR data, with potentially important implications for parameterizations of albedo, heat flux, and ice rheology.

(2) A correlation existing between persistent cyclonic circulation and reduced ice concentration in 1980, with less strong relationships in other years, provides some support for the hypothesis of ice divergence beneath low-pressure systems. Changes in ice concentration may also be associated with other synoptic patterns, and may require a complex combination and timing of winds, temperatures, ice conditions, and ice history to produce large changes in ice concentration. 
The analyses presented above are exploratory in nature. Correlations alone do not prove the existence of interactions, but merely demonstrate similar behaviour. Nevertheless, our results reinforce the conclusion of Zwally and Walsh (1987) that major synoptic events can have an effect on Arctic ice conditions lasting for several weeks. Physically, a strong cyclone system, coming after the snow cover has largely melted, should disrupt the ice by wind action. Reduced compactness would then permit divergent ice motion to predominate. It is not known whether the resulting open water could provide a significant energy source to help maintain the cyclone's intensity. Diagnostic analysis of the 1980 case is planned to examine this question. Future work will expand beyond the single-location analyses to search for spatial and temporal linkages between atmospheric and ice conditions.

\section{ACKNOWLEDGEMENTS}

This work has been supported under U.S. National Science Foundation grant DPP-85-20883. We wish to thank the reviewers for their helpful comments.

\section{REFERENCES}

Anderson, M.R. 1987. The onset of spring melt in first-year ice regions of the Arctic as determined from scanning multichannel microwave radiometer data for 1979 and 1980. J. Geophys. Res., 92(C12), 13153-13163.

Barry, R.G. 1983. Arctic Ocean ice and climate: perspectives on a century of polar research. Ann. Assoc. Am. Geogr., 73(4), 485-501.

Campbell, W.J., P. Gloersen, and H.J. Zwally. 1984. Aspects of Arctic sea ice observable by sequential passive microwave observations from the Nimbus-5 satellite. In Dyer, I. and C. Chryssostomidis, eds. Arctic technology and policy. Washington, DC, etc., Hemisphere Publishing, 197-222.

Cavalieri, D.J., P. Gloersen, and W.J. Campbell. 1984. Determination of sea ice parameters with the NIMBUS 7 SMMR. J. Geophys. Res., 89(D4), 5355-5369.
Crane, R.G., R.G. Barry, and H.J. Zwally. 1982. Analysis of atmosphere-sea ice interactions in the Arctic Basin using ESMR microwave data. Int. J. Remote Sensing, 3(3), 259-276.

Gloersen, P., H.J. Zwally, A.T.C. Chang, D.K.Hall, W.J. Campbell, and R.O. Ramseier. 1978. Time-dependence of sea-ice concentration and multiyear ice fraction in the Arctic Basin. Boundary-Layer Meteorol., 13(1-4), 339-359.

Hibler, W.D., III. 1974. Differential sea-ice drift. II. Comparison of mesoscale strain measurements to linear drift theory predictions. J. Glaciol., 13(69), 457-471.

Hibler, W.D., III. 1979. A dynamic thermodynamic sea ice model. J. Phys. Oceanogr., 9(4), 815-846.

McLaren, A.S. Unpublished. The under-ice thickness distribution of the Arctic Basin as recorded in 1958 and 1970. (Ph.D. thesis, University of Colorado, 1986.)

McLaren, A.S., M.C. Serreze, and R.G. Barry. 1987. Seasonal variations of sea ice motion in the Canada Basin and their implications. Geophys. Res. Lett., 14(11), 1123-1126.

Parkinson, C.L., J. Comiso, H.J. Zwally, D.J. Cavalieri, P. Gloersen, and W.J. Campbell. 1987. Arctic sea ice, 1973-1976: satellite passive-microwave observations. Washington, DC, National Aeronautics and Space Administration. (NASA SP-489.)

Thorndike, A.S. and R. Colony. 1980. Arctic Ocean Buoy Program data report: 1 January 1979 - 31 December 1979. Seattle, WA, University of Washington. Polar Science Center.

Thorndike, A.S. and R. Colony. 1981. Arctic Ocean Buoy Program data report: I January 1980 - 31 December 1980. Seattle, WA, University of Washington. Polar Science Center.

Thorndike, A.S. and R. Colony. 1983. Objective analysis of atmospheric pressure and sea ice motion over the Arctic Ocean. In Arctic Ocean Buoy Program data report: 1 January 1982 - 31 December 1982. Seattle, WA, University of Washington. Polar Science Center, 123-132.

Zwally, H.J. and J.E. Walsh. 1987. Comparison of observed and modeled ice motion in the Arctic Ocean. Ann. Glaciol., 9, 136-144. 